\title{
Traffic Characteristics of Protected/Permitted Left-Turn Signal Displays
}

\author{
By \\ David A. Noyce \\ Assistant Professor \\ Department of Civil and Environmental Engineering \\ University of Massachusetts \\ Amherst, MA 01003-5205 \\ Telephone: (413) 545-2509 \\ Fax: (413) 545-2840 \\ Email: noyce@ecs.umass.edu \\ Daniel B. Fambro \\ Associate Professor \\ Department of Civil Engineering \\ Texas A\&M University System \\ College Station, TX 77843-3135 \\ Telephone: (409) 845-1717 \\ Fax: (409) 845-6481 \\ Email: d-fambro@tamu.edu \\ Kent C. Kacir \\ Senior Associate Engineer \\ Kittelson \& Associates \\ 2200 W. Commercial Blvd., Suite 304 \\ Ft. Lauderdale, FL 33309 \\ Telephone: (954) 735-1245 \\ Fax: (954) 735-9025 \\ Email: kkacir@kittelson.com
}

Paper Number: 00-1699 Sponsoring Committee: A3A02

Prepared for the $79^{\text {th }}$ Annual Meeting of the

Transportation Research Board, Washington, D.C.

January, 2000

Length of Paper:

4,493 words, 7 figures + 5 tables @ 250 words each

7,493 equivalent words 


\title{
Traffic Characteristics of Protected/Permitted Left-Turn Signal Displays
}

\begin{abstract}
At least four variations of the permitted indication in protected/permitted left-turn (PPLT) control has been developed in an attempt to improve the level of driver understanding and safety. These variations replace the green ball permitted indication with either a flashing red ball, flashing yellow ball, flashing red arrow, or flashing yellow arrow indication. Additionally, the Manual on Uniform Traffic Control Devices (MUTCD) allows several PPLT signal display arrangements. The variability in indication and arrangement has led to a myriad of PPLT displays throughout the United States. The level of driver understanding related to each PPLT display type, and the associated impact on traffic operations and safety, has not been quantified.
\end{abstract}

This paper describes a study conducted to evaluate the operational characteristics associated with different PPLT signal displays. Specifically, this study quantifies saturation flow rate, start-up lost time, response time, and follow-up headway associated with selected PPLT displays.

No differences in saturation flow rate and start-up lost time were found due to the type of PPLT signal display. Saturation flow rates ranged from 1,770 to 2,400 vphgpl and were related to differences in driver behavior between geographic locations. The variation in start-up lost time and response time between locations was primarily related to differences in phase sequence. The flashing red permitted indications were associated with the longest follow-up headway times, since drivers are required to stop before turning left with a flashing red permitted indication. The shortest follow-up headway was associated with the five-section cluster display using a green ball indication.

Keywords: Protected/Permitted Left-Turn, Saturation Flow Rate, Start-Up Lost Time, Follow-Up Headway, Capacity 


\section{INTRODUCTION}

One relatively new type of left-turn signal phasing, designed to minimize the exclusive left-turn phase time requirements without decreasing capacity, is protected/permitted left-turn (PPLT) phasing. PPLT phasing provides an exclusive phase for left-turns as well as a permissive phase during which left-turns can be made if gaps in opposing through traffic allow, all within the same signal cycle (1). PPLT signal phasing is currently used at approximately 29 percent of the signalized intersections in the United States (2).

The Manual on Uniform Traffic Control Devices (MUTCD) provides guidelines for the use of traffic signal displays in the United States (3). To accommodate the various signal indications required for PPLT phasing, the MUTCD recommends a five-section signal display. There are several five-section PPLT signal display arrangements, including the horizontal, vertical, and cluster (4). Regardless of which signal display arrangement is selected, the MUTCD states that a green arrow indication shall be used for the protected left-turn phase and a circular green (green ball) indication for the permitted left-turn phase.

Problems with PPLT signal phasing, primarily related to the green ball permitted indication, have been identified but not resolved. Many traffic engineers argue that the MUTCD green ball permitted indication is adequate and properly conveys the intended message to the driver; however, other traffic engineers argue that the green ball indication is not well understood and therefore inadequate. The latter argument is based on the belief that drivers in a left-turn lane may interpret the green ball indication as a protected go indication, leading to a potential safety problem. To enhance driver understanding and safety, some traffic engineers believe that a different and/or unique permitted indication is needed.

At least four variations of the PPLT permitted indication have been developed in an attempt to improve driver understanding and safety. These unique indications replace the green ball indication and include a flashing red ball, flashing yellow ball, flashing red arrow, or flashing yellow arrow indication. There are also variations in signal display arrangement, signal display placement, and the use of supplemental signs. This variability in display types and indications has led to a myriad 
of PPLT signal displays and permitted indications used throughout the United States.

The National Committee on Uniform Traffic Control Devices (NCUTCD) is concerned that the variety of PPLT displays and indications may be confusing to drivers and may lead to driver error (5). The objective of the committee is to identify a PPLT signal display, or subset of displays, which provide the maximum level of driver understanding and safety. Drivers' understanding of each PPLT signal display type, and the associated impact on traffic operations and safety, has not been quantified.

This paper describes a study conducted to evaluate the traffic characteristics associated with different PPLT signal display types. Specifically, this study quantifies saturation flow rate, start-up lost time, response time, and follow-up headway associated with selected PPLT signal displays.

\section{BACKGROUND}

The notion of uniformity in traffic signal displays has been the basis of the MUTCD since its conception in 1935 (4). Uniform applications of traffic signal displays simplify the driving task by providing a consistent aid in the recognition and understanding of the intended message. The literature contains few studies that evaluate uniformity in traffic signal displays, and more specifically, evaluate the effect of the number and type of indications within each signal display arrangement. Nevertheless, the studies described in the literature indicate that no significant difference in driver understanding exists among signal display arrangements $(6,7,8,9)$.

Capacity and delay are two of the commonly used measures of effectiveness (MOEs) in evaluating signalized intersection operations (10). Left-turn capacity at a signalized intersection is based upon the concept of saturation flow. Saturation flow rate is defined as the maximum rate of flow that can pass through a given lane group under prevailing traffic and roadway conditions, assuming that the lane group has 100 percent of green time available (10). Saturation flow is usually reached after the fourth vehicle in queue has entered the intersection. 
At the beginning of each protected left-turn movement, the first several vehicles in the queue experience start-up time losses that result in their movement at less than the saturation flow rate ( 10 , 11). This start-up lost time is made up of the perception and reaction time (response time) associated with the change in signal indication along with the vehicle acceleration time to free flow speed. At the end of each movement, there is a portion of the clearance and change interval time that is not used for vehicle movements. This time is referred to as clearance lost time, and combined with start-up lost time, defines the total lost time for each phase.

Gap acceptance and follow-up headways also affect left-turn capacity. Gap acceptance refers to the time headways in the opposing traffic stream that left-turn drivers are willing to turn through during the permitted left-turn phase (10). The median time headway between two successive vehicles in the opposing traffic stream, accepted by left-turn drivers during the permitted phase, is referred to as the critical gap. Follow-up headway is the time span between the departure of a permitted left-turn vehicle and the departure of the next vehicle using the same gap under a condition of continuous queuing (10).

Left-turn delay can be evaluated by quantifying each of the operational variables described above and applying the procedures included in Chapter 9 of the Highway Capacity Manual (HCM) (10). When field measured values for the variables described above are not known, the HCM provides default values as follows:

- Ideal Saturation Flow Rate - 1,900 vphgpl;

- $\quad$ Lost Time (start-up + clearance) - 3.0 seconds/phase;

- Critical Gap (left-turn, four-lane major street) - 5.5 seconds; and

- Follow-Up Headway (left-turn, four-lane major street) - 2.1 seconds.

Researchers agree that PPLT signal phasing in a non-congested environment can improve capacity and reduce delay to the left-turn movement $(1,12,13)$. The literature contains limited information on the operational advantages of PPLT signal phasing based on signal displays, signal indications, or display placements used. 
Messer and Bonneson measured saturation flow rates and related capacity variables for left-turns near interchange ramp terminals (14). At 12 sites containing single left-turn lanes, saturation flow rates varied from $1,820 \mathrm{vphgpl}$ to $1,980 \mathrm{vphgpl,} \mathrm{with} \mathrm{an} \mathrm{average} \mathrm{of} \mathrm{1,895} \mathrm{vphgpl.} \mathrm{Higher} \mathrm{saturation}$ flow rates were found at locations with larger left-turn radii and with higher demand flow rates (i.e., traffic pressure).

Bonneson evaluated driver's response time to the leading left-turn indication, considering only the first vehicle in queue (6). Response time was defined as the start-up response time for the green arrow indication and the first left-turn driver. After evaluating 14 sites and 1,238 response times, Bonneson concluded that there were no significant differences among the five PPLT signal displays evaluated. Average response time for all left-turn signal displays was approximately 0.9 seconds. Shorter response times were found with the five-section horizontal display and five-section cluster display when the displays were mounted on a mast arm centered over the left-turn lane. In general, the difference in response times were less that 0.19 seconds.

Fambro evaluated saturation flow rates at signalized intersections using Dallas Phasing in Dallas, Texas (1). Four intersections were selected and 11 approaches studied using both leading and lagging phase sequences. Measured left-turn saturation flow rates ranged from 1,610 vphgpl to 2,126 vphgpl. Similar to the Messer study, higher left-turn saturation flow rates were found at locations with greater demand flow rates. The average saturation flow rate for all approaches evaluated was 1,910 vphgpl, nearly equivalent to the 1,900 vphgpl default value recommended by the HCM (10). Fambro also measured left-turn critical gap and follow-up headway as part of this study (1). Average critical gap for permitted left-turns at three intersections was 5.1 seconds and the average follow-up headway was 2.4 seconds. Each result was consistent with HCM default values. 


\section{METHODOLOGY}

To determine whether PPLT signal displays had an affect on traffic characteristics required a study that measured each variable at several intersections. Therefore, a study was designed to field measure saturation flow rate, start-up lost time, response time, and follow-up headway at each type of PPLT signal display and at different geographical regions of the United States.

Eight geographical locations were selected for analysis based on their PPLT signal display application. College Station and Dallas, Texas, Orlando, Florida, and Portland, Oregon were selected primarily because each used five-section signal displays with a green ball permitted indication. Cupertino, California, Dover, Delaware, Oakland County, Michigan, and Seattle, Washington were selected because of their use of a unique PPLT signal display with less than five display sections and a flashing permitted indication. Figure 1 depicts the signal displays evaluated in each location.

Three intersections were studied at each of the eight cities selected. In Dallas, two of the three intersections contained a lead-lag phasing sequence using Dallas Phasing. Dallas Phasing is a unique phasing scheme designed to eliminate the yellow trap. The left-turn phasing sequence changed from leading (AM peak) to lagging (PM peak) during each day of the study period. Therefore, each intersection approach was evaluated twice, under each phasing sequence, creating five study intersections in Dallas.

Criteria were established to qualify a typical intersection, meaning a right angle intersection with four approaches of two or three through lanes each, relatively flat grade, 12-foot lane width, no on-street parking, and no additional variables that directly impact the left-turn movement being evaluated. The intersections selected for study met these criteria. Intersections were different in PPLT display arrangement and corresponding permitted indication. 


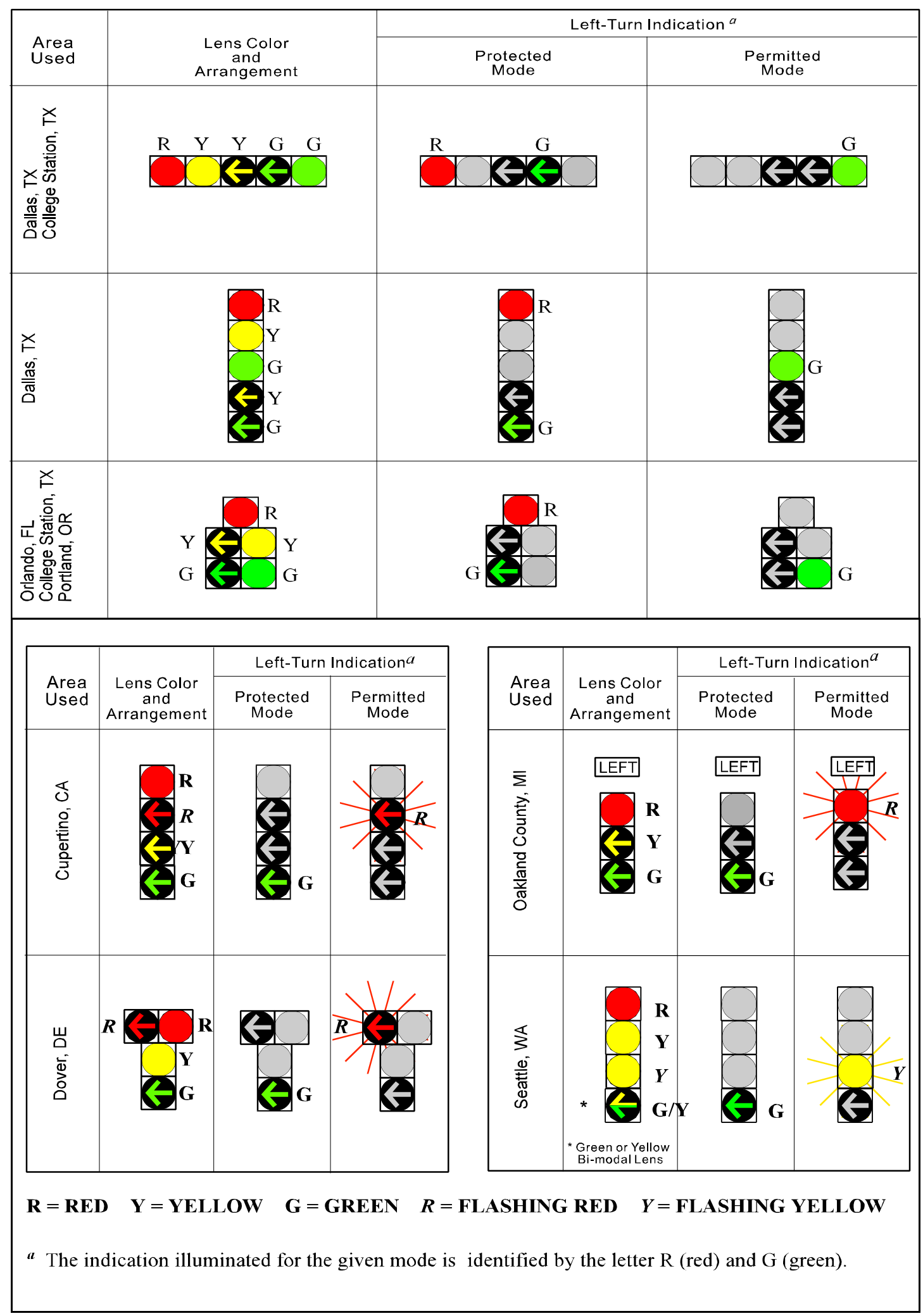

Figure 1 PPLT Signal Display Arrangements and Indications. 


\section{Traffic Studies}

Left-turn saturation flow rate, start-up lost time, response time, and follow-up headway data were evaluated at each intersection described in Table 1. Response time was defined as the first left-turn drivers' perception and reaction time to the onset of the protected green arrow. A sample size of approximately 30 valid left-turn queues were evaluated at each intersection. Headway data necessary to compute saturation flow rate, start-up lost time, response time, and follow-up headway were obtained using the HEADWAY program. HEADWAY is a DOS based computer program that records the computer clock time with each key stroke and computes the time differences between each. These time differences represent vehicle headway.

The observer was positioned near the intersection at a point where the stop bar (or similar reference point), the PPLT signal display, and the left-turn vehicle queue were clearly visible. Three signal cycles were carefully observed to identify approximate phase times, phase sequence, and duration of the all-red interval prior to the protected left-turn phase being evaluated. Knowing the preceding phase and its duration allowed the researcher to anticipate the start of the protected leftturn green phase. This knowledge, to the extent possible, ensured that the data collection equipment was activated simultaneously with the start of the protected left-turn green arrow indication. Pressing the appropriate key activated the HEADWAY program simultaneously with the activation of the green arrow indication. The computer key was then pressed as the front bumper of each vehicle in the queue (up to 10 vehicles maximum) crossed the reference line (11).

Research has shown that saturation flow most often begins with the fifth vehicle in queue (11). Thus, study procedures recommend that saturation flow rate estimates be obtained using headways from queued vehicle five through 10, and that queues of less than eight vehicles not be evaluated. Problems with these guidelines were experienced, primarily due to signal phasing limitations related to the protected left-turn green time available. Often, the left-turn green time was not sufficient for eight or more left-turn vehicles to proceed, even when there were more than eight vehicles in the queue. 
Table 1 Intersections Selected for Study

\begin{tabular}{|c|c|c|c|c|c|}
\hline City & Intersection & ID $^{a}$ & $\begin{array}{c}\text { PPLT } \\
\text { Display }^{b}\end{array}$ & $\mathbf{P I}^{c}$ & $\begin{array}{c}\text { LT } \\
\text { Phase }^{d}\end{array}$ \\
\hline \multirow{5}{*}{$\begin{array}{c}\text { Dallas } \\
\text { TX }\end{array}$} & Lovers Ln.@ Skillman Ave. & 1 & 5-Vert. & GB & Lead \\
\hline & Mockingbird Ln.@ Skillman Ave. & 2 & 5-Horz. & GB & D-Lead \\
\hline & Mockingbird Ln. @ Skillman Ave. & 3 & 5-Horz. & GB & D-Lag \\
\hline & Buckner Blvd.@ Garland Rd. & 4 & 5-Horz. & GB & D-Lead \\
\hline & Buckner Blvd.@ Garland Rd. & 5 & 5-Horz. & GB & D-Lag \\
\hline \multirow{3}{*}{$\begin{array}{c}\text { Dover } \\
\text { DE }\end{array}$} & Highway13@Court St. & 6 & 4-Cluster & FRA & Lead \\
\hline & Highway13@East Landing Rd. & 7 & 4-Cluster & FRA & Lead \\
\hline & Highway113@Little Creek Rd. & 8 & 4-Cluster & FRA & Lead \\
\hline \multirow{3}{*}{$\begin{array}{c}\text { Oakland } \\
\text { County } \\
\text { MI }\end{array}$} & Maple Ave. @ Orchard Lake Rd. & 9 & 3-Vert. & FRB & Lag \\
\hline & 14 Mile Rd. @ Orchard Lake Rd. & 10 & 3-Vert. & FRB & Lag \\
\hline & 13 Mile Rd. @ Orchard Lake Rd. & 11 & 3-Vert. & FRB & Lag \\
\hline \multirow{3}{*}{$\begin{array}{c}\text { College } \\
\text { Station } \\
\text { TX }\end{array}$} & University Dr. @ College Ave. & 12 & 5-Horz. & GB & Lead \\
\hline & SW Parkway@ Texas Ave. & 13 & 5-Horz. & GB & Lead \\
\hline & SW Parkway@ Southwood Dr. & 14 & 5-Cluster & GB & Lag \\
\hline \multirow{3}{*}{$\begin{array}{l}\text { Seattle } \\
\text { WA }\end{array}$} & South Lander St. @ $1^{\text {st }}$ Ave. & 15 & 4-Vert. & FYB & Lead \\
\hline & South Lander St. @ $4^{\text {th }}$ Ave. & 16 & 4-Vert. & FYB & Lead \\
\hline & Fairview Ave. @ Republican St. & 17 & 4-Vert. & FYB & Lead \\
\hline \multirow{3}{*}{$\begin{array}{c}\text { Portland } \\
\text { OR }\end{array}$} & Oleson Rd.@ Vermont St. & 18 & 5-Cluster & GB & Lead \\
\hline & NW Murray Blvd. @ Science Park & 19 & 5-Cluster & GB & Lead \\
\hline & La Bonita Dr. @ 72 ${ }^{\text {nd }}$ St. & 20 & 5-Cluster & GB & Lead \\
\hline \multirow{3}{*}{$\begin{array}{c}\text { Cupertino } \\
\text { CA }\end{array}$} & Pruneridge Dr.@ Hewlett Packard & 21 & 4-Vert. & FRA & Lead \\
\hline & Stevens Creek Blvd. @ Torre Dr. & 22 & 4-Vert. & FRA & Lead \\
\hline & Stevens Creek Blvd.@ Portal Ave. & 23 & 4-Vert. & FRA & Lead \\
\hline \multirow{3}{*}{$\begin{array}{c}\text { Orlando } \\
\text { FL }\end{array}$} & Orange Blossom Trail @ Princeton & 24 & 5-Cluster & GB & Lead \\
\hline & Orange Ave.@Kaley St. & 25 & 5-Cluster & GB & Lead \\
\hline & Orange Ave.@Michigan St. & 26 & 5-Cluster & GB & Lead \\
\hline
\end{tabular}

${ }^{a}$ Intersection Identification Number.

${ }^{b}$ Number of signal display sections (3, 4, or 5) - arrangement (Horizontal, Vertical, or Cluster).

${ }^{c}$ Permitted Indication $-\mathrm{G}=$ Green; $\mathrm{Y}=$ Yellow; $\mathrm{R}=$ Red; $\mathrm{B}=$ Ball; $\mathrm{A}=$ Arrow; $\mathrm{F}=$ Flashing.

${ }^{d}$ Left-turn phasing. $\mathrm{D}=$ Dallas Phasing. 
At intersections where left-turn queues exceeded eight vehicles, there was often sufficient green time to allow seven vehicles to proceed. Thus, the minimum left-turn queue length requirement was revised from eight to seven or more vehicles. In addition to queue length, headway data were not obtained if a heavy vehicle (six or more wheels) was located in one of the first seven positions of the queue. Saturation flow data were obtained primarily during the morning and evening peak volume periods, but not during periods of oversaturation.

Start-up lost time (seconds) was computed by summing the difference between the average headway of each of the first four vehicles in the left-turn queue $\left(\mathrm{h}_{1-4}\right)$ and the saturation headway (h) (11). Occasionally, saturation flow was not reached until after the fifth vehicle in queue. In these situations, the difference in average headway between the fifth vehicle in queue and the saturation headway was also included in the start-up lost time calculation.

Average response time (seconds) was computed by averaging the time between the onset of the protected green arrow and the passage of a reference point for the first left-turn vehicle in queue. These times were obtained from all left-turn queues in which data were obtained, regardless of the total queue length. Average follow-up headways (seconds) were computed in a consistent procedure.

\section{STUDY RESULTS}

\section{Saturation Flow Rate}

Table 2 presents the average saturation flow rate data along with the PPLT signal display, permitted indication, and left-turn phasing sequence that existed at each intersection. Note that intersections 16 and 17 in Seattle, intersection 18 in Portland, and intersection 23 in Cupertino did not have left-turn queues greater than seven vehicles (i.e., saturation flow rate could not be measured) and were not included in this analysis. 
Table 2 Saturation Flow Rate Data

\begin{tabular}{|c|c|c|c|c|c|c|c|}
\hline \multirow[b]{2}{*}{ City } & \multirow[b]{2}{*}{ ID $^{a}$} & \multirow{2}{*}{$\begin{array}{c}\text { PPLT } \\
\text { Display }^{b}\end{array}$} & \multirow[b]{2}{*}{$\mathbf{P I}^{c}$} & \multirow{2}{*}{$\begin{array}{l}\text { Left-Turn } \\
\text { Phasing }\end{array}$} & \multicolumn{3}{|c|}{ Saturation Flow Rate (vphgpl) } \\
\hline & & & & & No. ${ }^{d}$ & Average & $\mathbf{S D}^{e}$ \\
\hline \multirow{5}{*}{$\begin{array}{l}\text { Dallas } \\
\text { TX }\end{array}$} & 1 & 5-Vert. & GB & Lead & 30 & 2,200 & 36 \\
\hline & 2 & 5-Horz. & GB & Dallas-Lead & 34 & 2,210 & 36 \\
\hline & 3 & 5-Horz. & GB & Dallas-Lag & 15 & 2,320 & 97 \\
\hline & 4 & 5-Horz. & GB & Dallas-Lead & 30 & 2,090 & 98 \\
\hline & 5 & 5-Horz. & GB & Dallas-Lag & 36 & 2,060 & 59 \\
\hline \multirow{3}{*}{$\begin{array}{l}\text { Dover } \\
\text { DE }\end{array}$} & 6 & 4-Cluster & FRA & Lead & 23 & 2,210 & 152 \\
\hline & 7 & 4-Cluster & FRA & Lead & 38 & 1,980 & 20 \\
\hline & 8 & 4-Cluster & FRA & Lead & 37 & 2,000 & 118 \\
\hline \multirow{3}{*}{$\begin{array}{l}\text { Oakland } \\
\text { County } \\
\text { MI }\end{array}$} & 9 & 3-Vert. & FRB & Lag & 50 & 2,170 & 111 \\
\hline & 10 & 3-Vert. & FRB & Lag & 54 & 2,400 & 86 \\
\hline & 11 & 3-Vert. & FRB & Lag & 50 & 2,400 & 52 \\
\hline \multirow{3}{*}{$\begin{array}{c}\text { College } \\
\text { Station } \\
\text { TX }\end{array}$} & 12 & 5-Horz. & GB & Lead & 42 & 1,970 & 61 \\
\hline & 13 & 5-Horz. & GB & Lead & 45 & 2,020 & 78 \\
\hline & 14 & 5-Cluster & GB & Lag & 23 & 2,040 & 57 \\
\hline \multirow{3}{*}{$\begin{array}{l}\text { Seattle } \\
\text { WA }\end{array}$} & 15 & 4-Vert. & FYB & Lead & 15 & 1,770 & 3 \\
\hline & 16 & 4-Vert. & FYB & Lead & --- & --- & --- \\
\hline & 17 & 4-Vert. & FYB & Lead & --- & --- & --- \\
\hline \multirow{3}{*}{$\begin{array}{l}\text { Portland } \\
\text { OR }\end{array}$} & 18 & 5-Cluster & GB & Lead & --- & --- & --- \\
\hline & 19 & 5-Cluster & GB & Lead & 29 & 1,870 & 40 \\
\hline & 20 & 5-Cluster & GB & Lead & 15 & 1,980 & 7 \\
\hline \multirow{3}{*}{$\begin{array}{c}\text { Cupertino } \\
\text { CA }\end{array}$} & 21 & 4-Vert. & FRA & Lead & 29 & 2,060 & 48 \\
\hline & 22 & 4-Vert. & FRA & Lead & 24 & 1,940 & 146 \\
\hline & 23 & 4-Vert. & FRA & Lead & --- & --- & --- \\
\hline \multirow{3}{*}{$\begin{array}{l}\text { Orlando } \\
\text { FL }\end{array}$} & 24 & 5-Cluster & GB & Lead & 47 & 2,070 & 42 \\
\hline & 25 & 5-Cluster & GB & Lead & 60 & 2,070 & 61 \\
\hline & 26 & 5-Cluster & GB & Lead & 56 & 1,960 & 102 \\
\hline
\end{tabular}

${ }^{a}$ Intersection Identification Number.

${ }^{b}$ Number of signal display sections (3, 4, or 5) - arrangement (Horizontal, Vertical, or Cluster).

${ }^{c}$ Permitted Indication $-\mathrm{G}=$ Green; $\mathrm{Y}=$ Yellow; $\mathrm{R}=$ Red; $\mathrm{B}=\mathrm{Ball}$; $\mathrm{A}=$ Arrow; $\mathrm{F}=$ Flashing.

${ }^{d}$ Number of Observations.

${ }^{e}$ Standard Deviation. 
Left-turn saturation flow rates ranged from 2,400 vphgpl at intersection 11 in Oakland County to 1,770 vphgpl at intersection 15 in Seattle. The average saturation flow rate was 2,080 vphgpl. Average saturation flow rate for the 16 intersection approaches with a leading left-turn phasing sequence and for the six approaches with a lagging left-turn phasing sequence were 2,030 vphgpl and 2,230 vphgpl, respectively. Each of these average saturation flow rate values exceeded the 1,900 vphgpl ideal saturation flow rate default value described in the HCM ( 10$)$.

Figure 2 shows the average saturation flow rate (horizontal bar) and 95 percent confidence interval (CIs) (vertical line) for each study location. To explain the variability in saturation flow rates between locations, a statistical analysis was completed. Three factors were considered; location, signal display, and signal phasing. The results of the statistical analysis found only the location factor to be significant, at a 99 percent level of confidence.

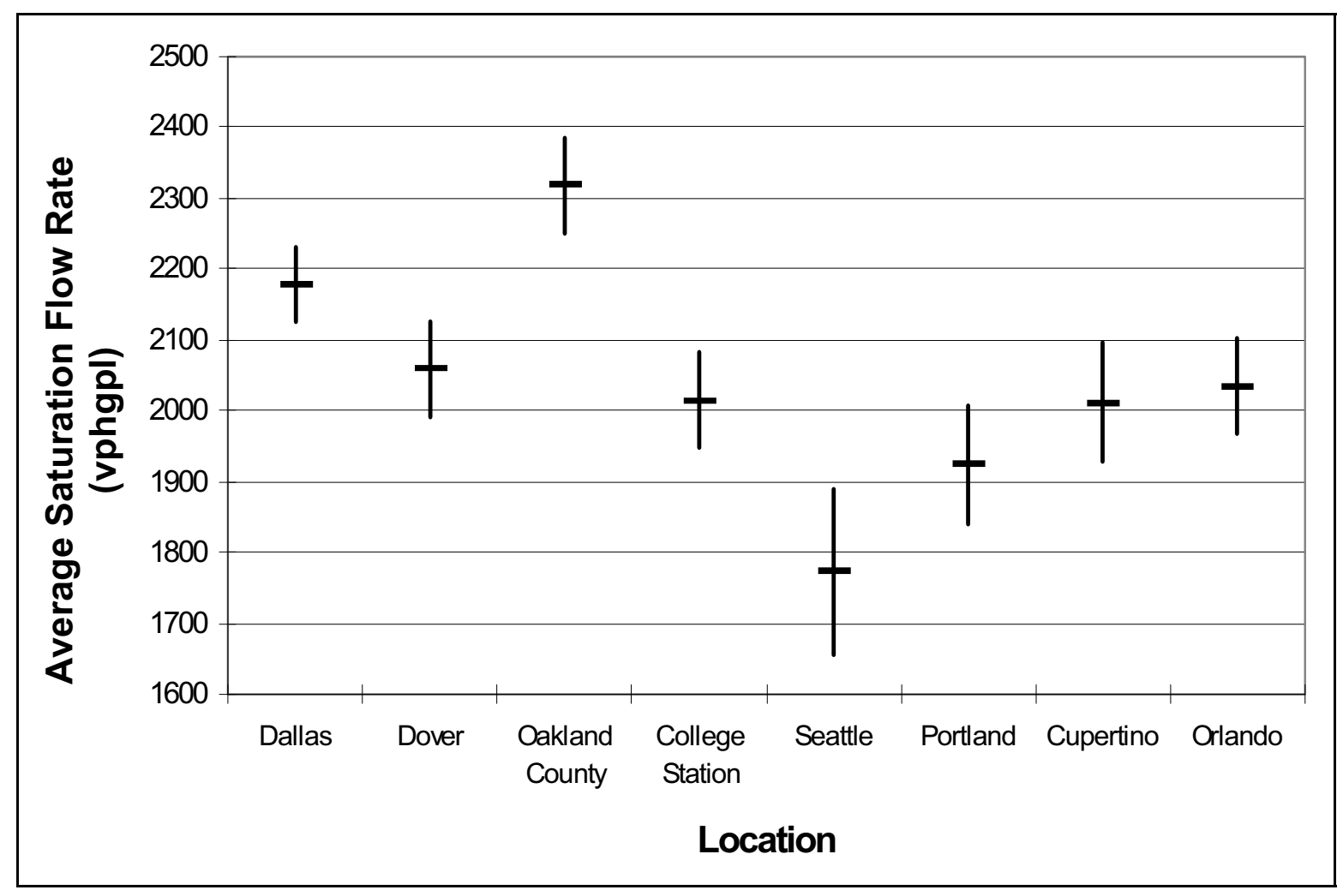

Figure 2 Average Saturation Flow Rate and 95 Percent CIs by Location. 
The results suggest that the differences in average saturation flow rate were primarily due to differences in operational characteristics and driver behavior between each study location. The highest saturation flow rates were found at locations where demand flow rates approached congested levels resulting in higher traffic pressure and more aggressive driving. The type of PPLT signal display and the signal phasing sequence were not significant contributors to the differences in average saturation flow rate.

\section{Through Movement Saturation Flow Rate}

A supplemental study was conducted on through movement saturation flow rate to determine if similar differences between locations existed. Eight intersections were randomly selected (one intersection from each location) and through movement saturation headway from a minimum of 30 queues of seven or more vehicles was measured. This methodology resulted in the evaluation of approximately 300 through movement saturation headways at each location.

As shown in Figure 3, geographic location was found to be a statistically significant variable in through movement average saturation flow rate, similar to the findings of the left-turn movement analysis. In fact, a comparison of Figures 2 and 3 finds the location based rank order of average saturation flow rate nearly identical. Oakland County, Michigan had the highest average through movement saturation flow rate at 2,220 vphgpl and Seattle, Washington the lowest at 1,900 vphgpl. Similar to the left-turn results, saturation flow rates consistently exceeded the 1,900 vphgpl HCM default value. The through movement saturation flow rate in Oakland County and Dover were not statistically different; however, Oakland County's results were significantly greater than the remaining locations. Moreover, Seattle was found to have significantly lower through movement saturation flow rate than Oakland County, Dover, and Dallas.

The results of the left-turn and through movement saturation flow rate analyses were compared, as shown in Figure 4. The slope of the trend line indicated that the left-turn and through movement saturation flow rates had similar magnitudes. Average left-turn saturation flow rate for all locations was 2,080 vphgpl, compared with 2,110 vphgpl for the through movement. The ratio of left-turn 


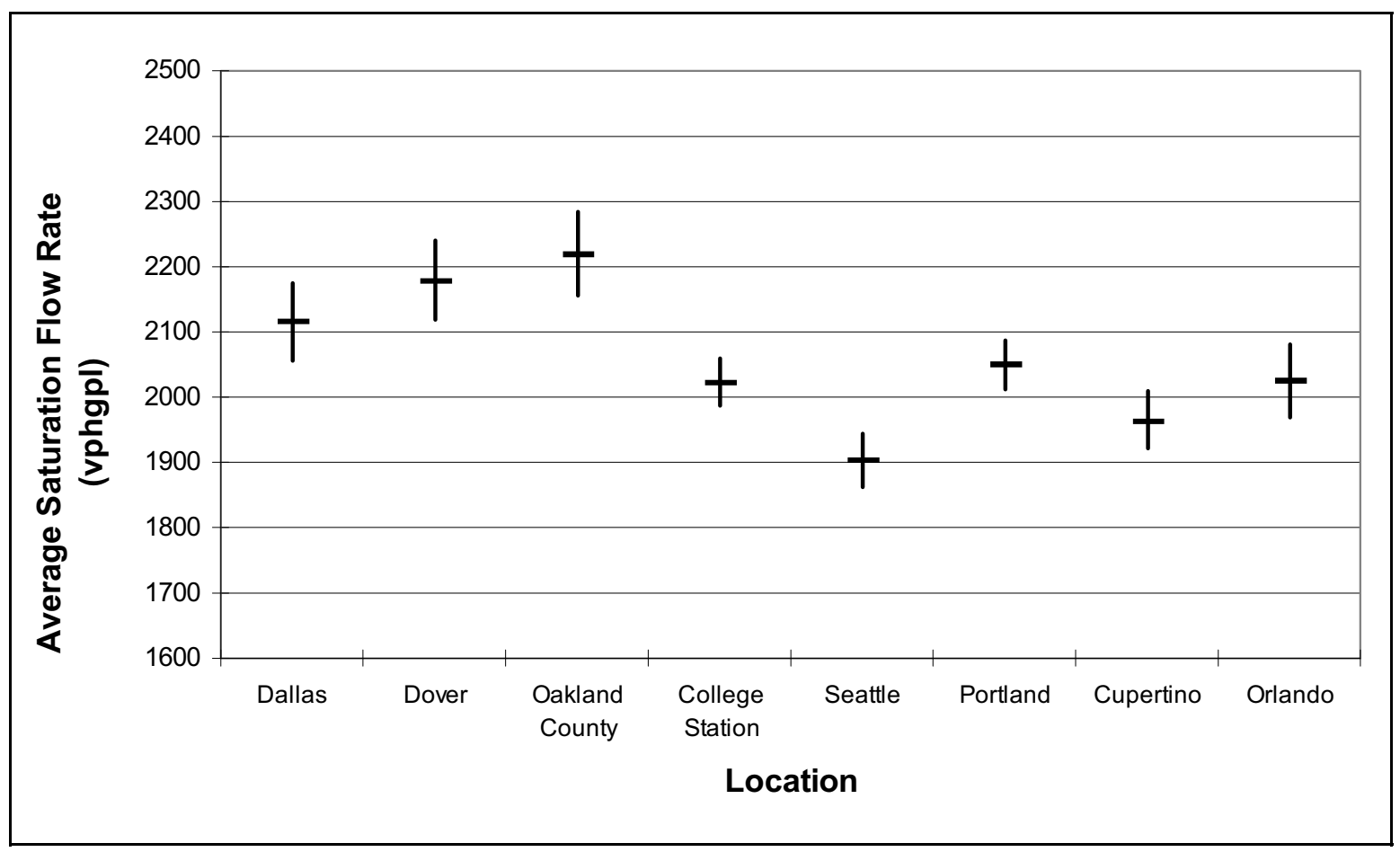

Figure 3 Average Through Movement Saturation Flow Rate and CIs by Location.

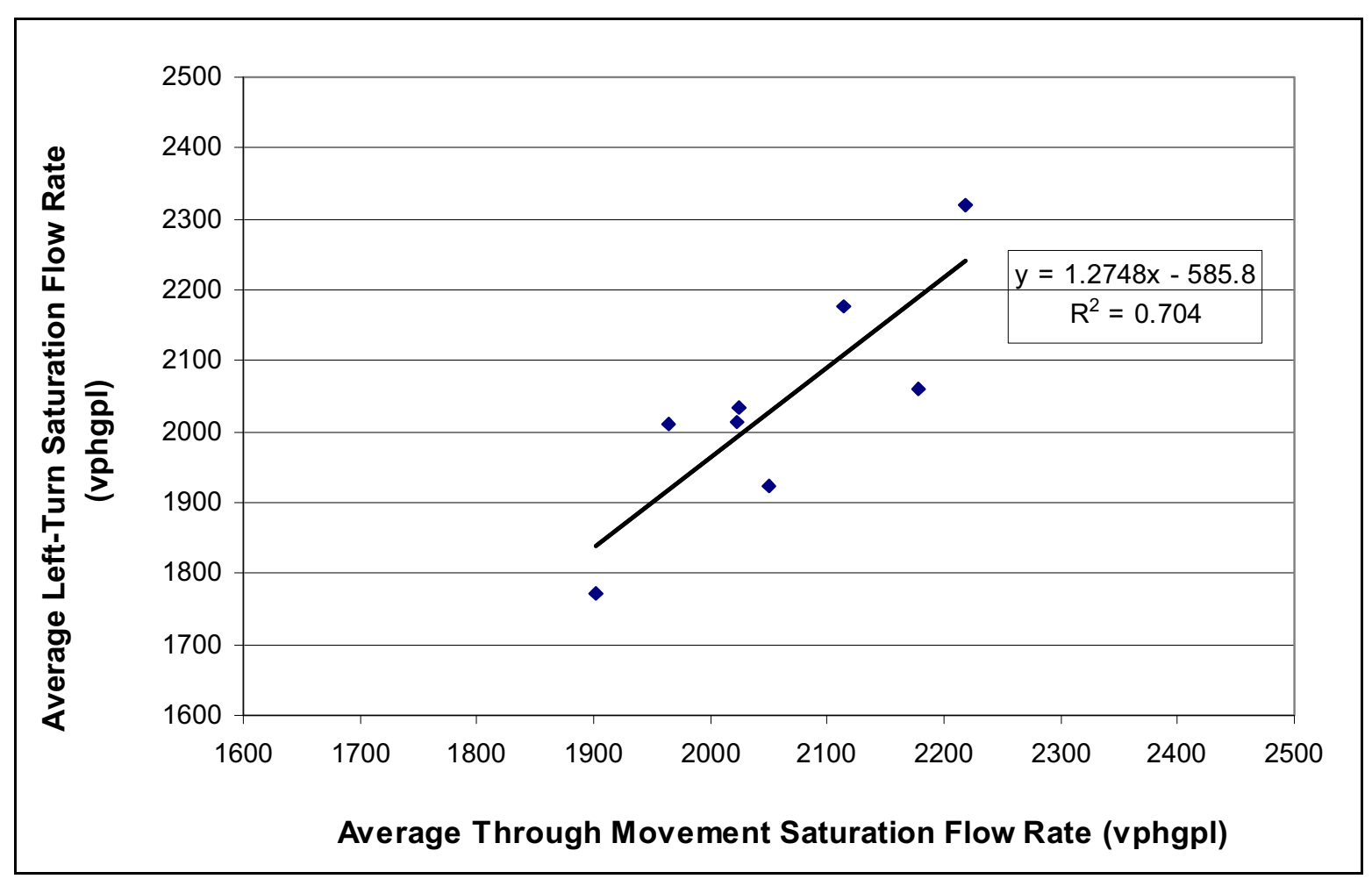

Figure 4 Comparison of Left-Turn and Through Movement Saturation Flow Rates. 
saturation flow rate to through movement saturation flow rate for each location ranged from 0.91 in Seattle to 1.0 in Cupertino, Oakland County, and Orlando. The average ratio for all locations was 0.96 , similar to the 0.95 left-turn adjustment factor for exclusive lane and protected left-turn phasing described in the HCM (10). It was concluded that the differences in left-turn and through movement saturation flow rates were due to differences in driver behavior at each study location.

\section{Start-up Lost Time}

Table 3 presents the results of the start-up lost time analysis. Since saturation flow rate could not be determined at intersections 16 and 17 in Seattle, intersection 18 in Portland, and intersection 23 in Cupertino, start-up lost time could not be computed at these locations. Start-up lost time ranged from 0.3 seconds in Oakland County to 2.7 seconds in Orlando. Average start-up lost time

for all locations was 1.6 seconds. Considering left-turn phase sequence, average start-up lost time was 1.9 seconds with a leading sequence (16 approaches) and 0.7 seconds with a lagging sequence (six approaches). The HCM default value for start-up lost time of 3.0 seconds/phase is considerably higher than the study results, although the HCM value also includes clearance lost time (3).

Figure 5 depicts the average start-up lost time and 95 percent CIs for each phasing sequence. A statistical analysis considering location, signal display, and signal phasing sequence as variables was completed to identify the source of variability in the data. The results suggested that the differences in average start-up lost time were primarily due to differences in PPLT signal phasing. Left-turn phasing sequence was statistically significant at a 98 percent level of confidence. Lagging left-turn signal phasing was found to have lower start-up lost times than leading left-turn signal phasing across all locations. 
Table 3 Start-Up Lost Time

\begin{tabular}{|c|c|c|c|c|c|c|c|}
\hline \multirow[b]{2}{*}{ City } & \multirow[b]{2}{*}{ ID $^{a}$} & \multirow{2}{*}{$\begin{array}{c}\text { PPLT } \\
\text { Display }^{b}\end{array}$} & \multirow[b]{2}{*}{$\mathbf{P I}^{c}$} & \multirow{2}{*}{$\begin{array}{c}\text { Left-Turn } \\
\text { Phasing }\end{array}$} & \multicolumn{3}{|c|}{ Start-Up Lost Time (sec) } \\
\hline & & & & & No. ${ }^{d}$ & Average & $\mathbf{S D}^{e}$ \\
\hline \multirow{5}{*}{$\begin{array}{l}\text { Dallas } \\
\text { TX }\end{array}$} & 1 & 5-Vert. & GB & Lead & 30 & 1.9 & 0.3 \\
\hline & 2 & 5-Horz. & GB & Dallas-Lead & 34 & 2.1 & 0.4 \\
\hline & 3 & 5-Horz. & GB & Dallas-Lag & 15 & 0.8 & 0.7 \\
\hline & 4 & 5-Horz. & GB & Dallas-Lead & 30 & 1.7 & 0.5 \\
\hline & 5 & 5-Horz. & GB & Dallas-Lag & 36 & 0.8 & 0.2 \\
\hline \multirow{3}{*}{$\begin{array}{l}\text { Dover } \\
\text { DE }\end{array}$} & 6 & 4-Cluster & FRA & Lead & 23 & 1.7 & 0.2 \\
\hline & 7 & 4-Cluster & FRA & Lead & 38 & 2.3 & 0.4 \\
\hline & 8 & 4-Cluster & FRA & Lead & 37 & 2.0 & 0.8 \\
\hline \multirow{3}{*}{$\begin{array}{l}\text { Oakland } \\
\text { County } \\
\text { MI }\end{array}$} & 9 & 3-Vert. & FRB & Lag & 50 & 0.3 & 0.2 \\
\hline & 10 & 3-Vert. & FRB & Lag & 54 & 0.7 & 0.1 \\
\hline & 11 & 3-Vert. & FRB & Lag & 50 & 0.9 & 0.3 \\
\hline \multirow{3}{*}{$\begin{array}{c}\text { College } \\
\text { Station } \\
\text { TX }\end{array}$} & 12 & 5-Horz. & GB & Lead & 42 & 2.2 & 0.3 \\
\hline & 13 & 5-Horz. & GB & Lead & 45 & 1.9 & 0.4 \\
\hline & 14 & 5-Cluster & GB & Lag & 23 & 0.8 & 0.3 \\
\hline \multirow{3}{*}{$\begin{array}{l}\text { Seattle } \\
\text { WA }\end{array}$} & 15 & 4-Vert. & FYB & Lead & 15 & 2.3 & 0.1 \\
\hline & 16 & 4-Vert. & FYB & Lead & --- & --- & --- \\
\hline & 17 & 4-Vert. & FYB & Lead & --- & --- & --- \\
\hline \multirow{3}{*}{$\begin{array}{l}\text { Portland } \\
\text { OR }\end{array}$} & 18 & 5-Cluster & GB & Lead & --- & --- & --- \\
\hline & 19 & 5-Cluster & GB & Lead & 29 & 1.1 & 0.1 \\
\hline & 20 & 5-Cluster & GB & Lead & 15 & 1.5 & 0.1 \\
\hline \multirow{3}{*}{$\begin{array}{c}\text { Cupertino } \\
\text { CA }\end{array}$} & 21 & 4-Vert. & FRA & Lead & 29 & 1.0 & 0.8 \\
\hline & 22 & 4-Vert. & FRA & Lead & 24 & 1.3 & 0.2 \\
\hline & 23 & 4-Vert. & FRA & Lead & --- & --- & --- \\
\hline \multirow{3}{*}{$\begin{array}{l}\text { Orlando } \\
\text { FL }\end{array}$} & 24 & 5-Cluster & GB & Lead & 47 & 2.7 & 0.1 \\
\hline & 25 & 5-Cluster & GB & Lead & 60 & 1.8 & 0.6 \\
\hline & 26 & 5-Cluster & GB & Lead & 56 & 2.2 & 1.0 \\
\hline
\end{tabular}

${ }^{a}$ Intersection Identification Number.

${ }^{b}$ Number of signal display sections (3, 4, or 5) - arrangement (Horizontal, Vertical, or Cluster).

$c$ Permitted Indication - $\mathrm{G}=$ Green; $\mathrm{Y}=$ Yellow; $\mathrm{R}=$ Red; $\mathrm{B}=$ Ball; $\mathrm{A}=$ Arrow; $\mathrm{F}=$ Flashing.

${ }^{d}$ Number of Observations.

e Standard Deviation. 


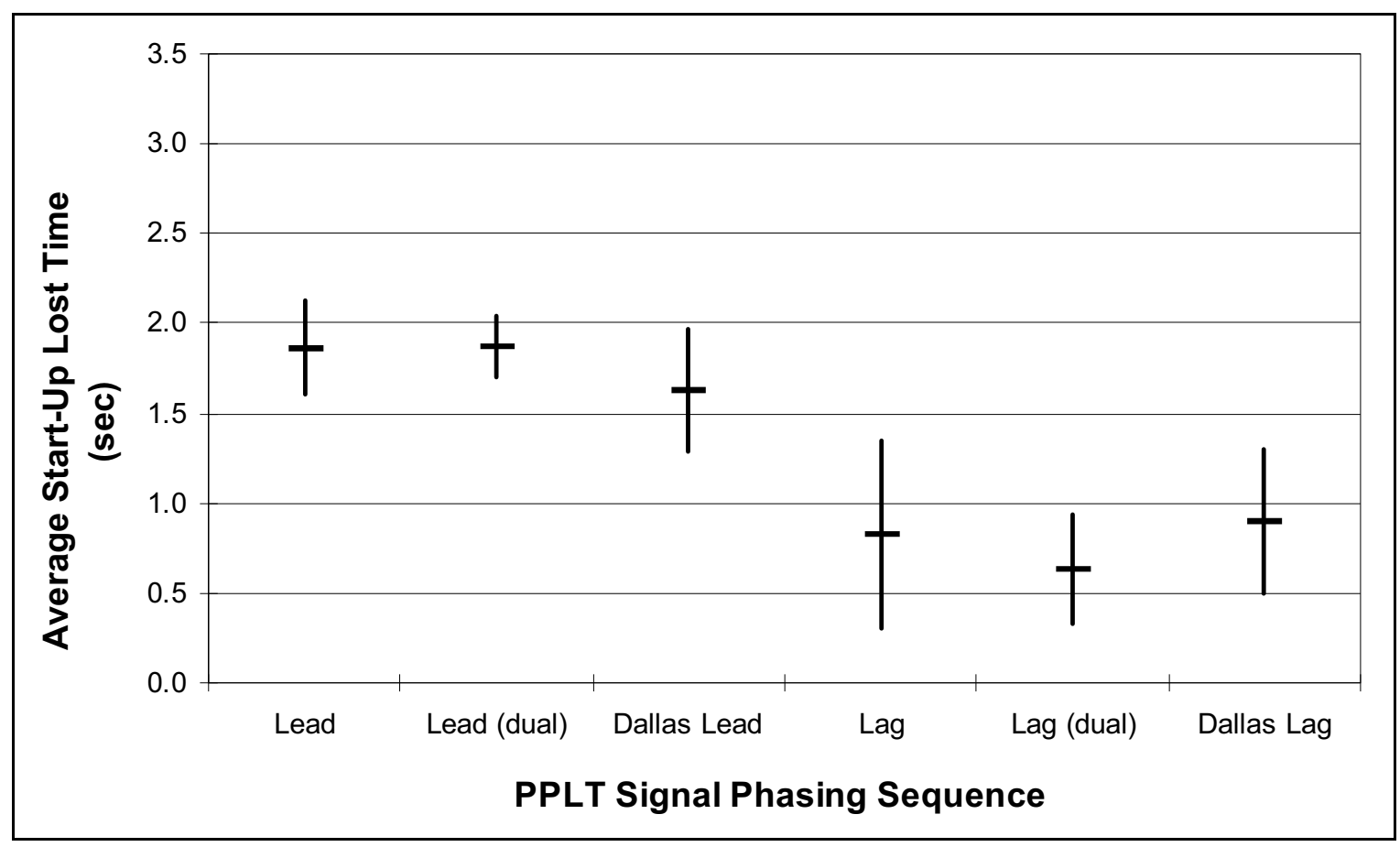

Figure 5 Average Start-Up Lost Time and 95 Percent CIs by Phasing.

Lower start-up lost time during the lagging left-turn phasing sequence was primarily due to drivers anticipation of the protected left-turn phase onset. Drivers in Dallas and Oakland County appeared knowledgeable of the left-turn phase sequence and often began the protected left-turn maneuver during the final seconds of the through movement clearance interval. This anticipation meant that the perception and reaction time components of start-up lost time were primarily consumed during the preceding yellow and all red intervals. By the time the left-turn green arrow indication was presented, the left-turn queue was moving at or near the saturation flow rate.

Start-up lost times with a leading left-turn phasing sequence were approximately 1.0 seconds higher than with a lagging left-turn phasing sequence. An average of 1.9 seconds of start-up lost time with a leading left-turn phasing sequence was consistent with HCM values. The HCM indicates a total lost time default value of 3.0 seconds/phase, of which a significantly greater proportion is due to start-up lost time (10). 


\section{Response Time}

Table 4 presents that average response time found at each intersection along with pertinent PPLT signal display information. Average response times ranged from 1.5 seconds in Oakland County to a high of 3.2 seconds in Orlando. The average response time for all study locations was 2.5 seconds. Average response time was 2.7 seconds for the leading left-turn phase sequence (20 approaches) and 1.8 seconds for the lagging left-turn phase sequence (six approaches).

Figure 6 presents the average response time and 95 percent CIs by phasing sequence. The results of a statistical analysis indicated that the variability in average response time was due to differences in both the PPLT signal display and the left-turn phasing sequence present at each location. The statistical procedures indicated that phasing sequence ( 99.9 percent level of confidence) explained more of the variability in average response time than display type or location; however, each factor was a significant contributor. Correlation between PPLT signal display and both signal phasing sequence and location was expected because of the dependence of these variables in the data set.

Similar to the start-up lost time results, a lagging left-turn phasing sequence resulted in lower response times. This result was expected since start-up lost time and response time are a function of similar measures. 
Table 4 Average Response Time by Intersection

\begin{tabular}{|c|c|c|c|c|c|c|c|}
\hline \multirow[b]{2}{*}{ City } & \multirow[b]{2}{*}{ ID $^{a}$} & \multirow{2}{*}{$\begin{array}{c}\text { PPLT } \\
\text { Display }^{b} \\
\end{array}$} & \multirow[b]{2}{*}{$\mathbf{P I}^{c}$} & \multirow{2}{*}{$\begin{array}{c}\text { Left-Turn } \\
\text { Phasing }\end{array}$} & \multicolumn{3}{|c|}{ Response Time (sec) } \\
\hline & & & & & No. ${ }^{d}$ & Average & $\mathbf{S D}^{e}$ \\
\hline \multirow{5}{*}{$\begin{array}{l}\text { Dallas } \\
\text { TX }\end{array}$} & 1 & 5-Vert. & GB & Lead & 50 & 2.5 & 0.5 \\
\hline & 2 & 5-Horz. & GB & Dallas-Lead & 50 & 2.6 & 0.6 \\
\hline & 3 & 5-Horz. & GB & Dallas-Lag & 50 & 1.8 & 0.4 \\
\hline & 4 & 5-Horz. & GB & Dallas-Lead & 50 & 2.4 & 0.5 \\
\hline & 5 & 5-Horz. & GB & Dallas-Lag & 50 & 1.8 & 0.4 \\
\hline \multirow{3}{*}{$\begin{array}{c}\text { Dover } \\
\text { DE }\end{array}$} & 6 & 4-Cluster & FRA & Lead & 50 & 2.8 & 0.7 \\
\hline & 7 & 4-Cluster & FRA & Lead & 67 & 2.6 & 0.7 \\
\hline & 8 & 4-Cluster & FRA & Lead & 50 & 2.7 & 0.7 \\
\hline \multirow{3}{*}{$\begin{array}{c}\text { Oakland } \\
\text { County } \\
\text { MI }\end{array}$} & 9 & 3-Vert. & FRB & Lag & 73 & 1.5 & 0.5 \\
\hline & 10 & 3-Vert. & FRB & Lag & 72 & 1.8 & 0.4 \\
\hline & 11 & 3-Vert. & FRB & Lag & 62 & 1.9 & 0.5 \\
\hline \multirow{3}{*}{$\begin{array}{c}\text { College } \\
\text { Station } \\
\text { TX }\end{array}$} & 12 & 5-Horz. & GB & Lead & 57 & 3.1 & 0.9 \\
\hline & 13 & 5-Horz. & GB & Lead & 80 & 2.6 & 0.7 \\
\hline & 14 & 5-Cluster & GB & Lag & 50 & 2.0 & 0.5 \\
\hline \multirow{3}{*}{$\begin{array}{c}\text { Seattle } \\
\text { WA }\end{array}$} & 15 & 4-Vert. & FYB & Lead & 55 & 3.1 & 1.2 \\
\hline & 16 & 4-Vert. & FYB & Lead & 55 & 2.8 & 0.5 \\
\hline & 17 & 4-Vert. & FYB & Lead & 23 & 2.8 & 1.0 \\
\hline \multirow{3}{*}{$\begin{array}{l}\text { Portland } \\
\text { OR }\end{array}$} & 18 & 5-Cluster & GB & Lead & 55 & 2.4 & 0.9 \\
\hline & 19 & 5-Cluster & GB & Lead & 55 & 2.3 & 0.6 \\
\hline & 20 & 5-Cluster & GB & Lead & 53 & 2.2 & 0.6 \\
\hline \multirow{3}{*}{$\begin{array}{c}\text { Cupertino } \\
\text { CA }\end{array}$} & 21 & 4-Vert. & FRA & Lead & 78 & 2.4 & 0.7 \\
\hline & 22 & 4-Vert. & FRA & Lead & 50 & 2.5 & 0.8 \\
\hline & 23 & 4-Vert. & FRA & Lead & 50 & 2.5 & 0.5 \\
\hline \multirow{3}{*}{$\begin{array}{l}\text { Orlando } \\
\text { FL }\end{array}$} & 24 & 5-Cluster & GB & Lead & 50 & 3.2 & 0.9 \\
\hline & 25 & 5-Cluster & GB & Lead & 60 & 2.9 & 0.8 \\
\hline & 26 & 5-Cluster & GB & Lead & 56 & 3.0 & 0.9 \\
\hline
\end{tabular}

${ }^{a}$ Intersection Identification Number.

${ }^{b}$ Number of signal display sections (3, 4, or 5) - arrangement (Horizontal, Vertical, or Cluster).

${ }^{c}$ Permitted Indication $-\mathrm{G}=$ Green; $\mathrm{Y}=$ Yellow; $\mathrm{R}=$ Red; $\mathrm{B}=$ Ball; $\mathrm{A}=$ Arrow; $\mathrm{F}=$ Flashing.

${ }^{d}$ Number of Observations.

e Standard Deviation. 


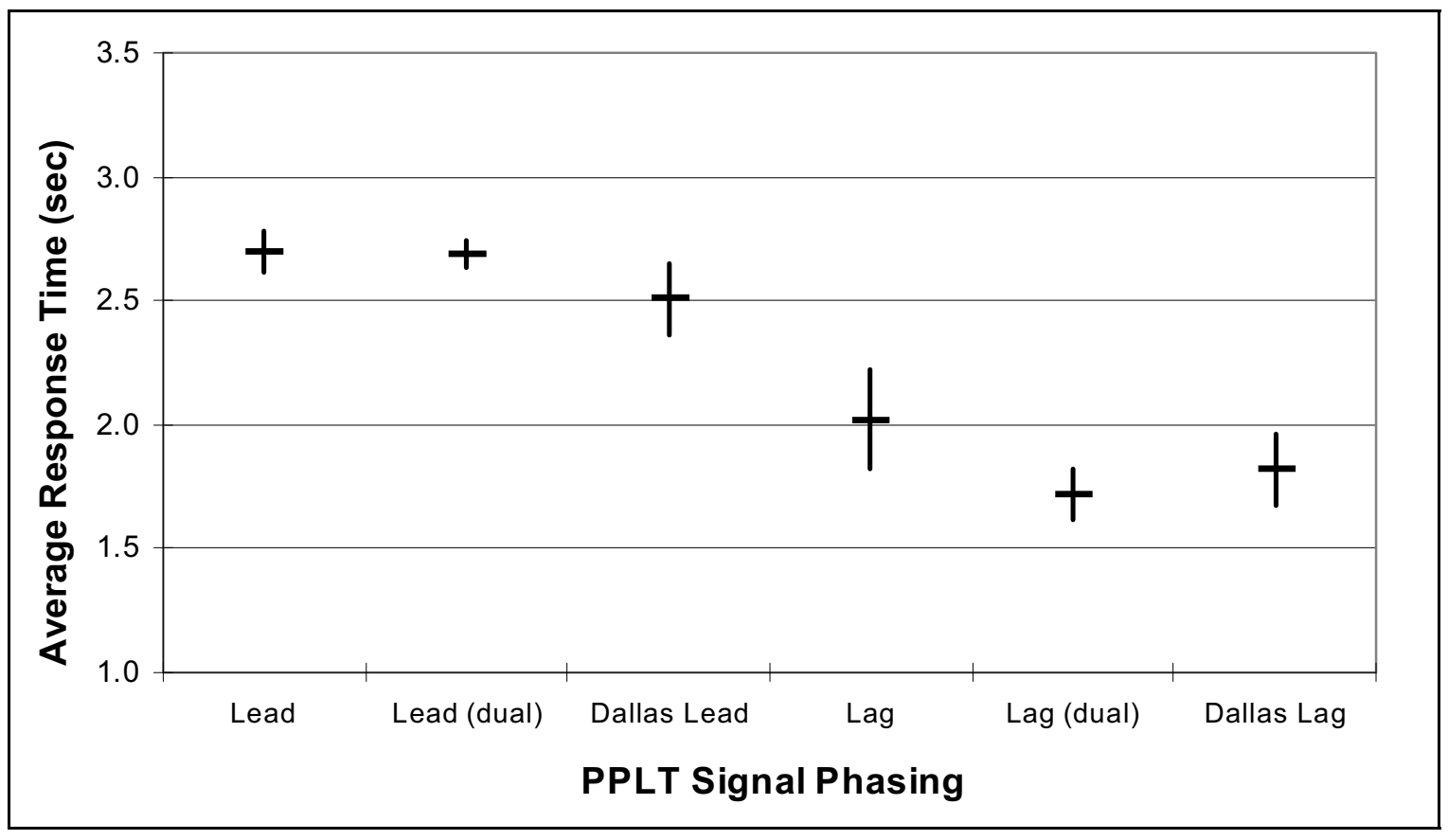

Figure 6 Average Response Time and 95 Percent CIs by PPLT Signal Phasing.

\section{Follow-Up Headway}

Table 5 presents that average follow-up headway time at each intersection. Recall that the follow-up headway pertains to the permitted left-turn phase. The average follow-up headway for all locations was 2.4 seconds. Average follow-up headway was 2.6 seconds for the flashing red permitted indications. Dover $(2.8 \mathrm{sec})$, Cupertino $(2.5 \mathrm{sec})$, and Oakland County $(2.4 \mathrm{sec})$, all which use a flashing red permitted indication, had the highest follow-up headway times. Both Dover and Cupertino use a supplemental sign that reads STOP THEN YIELD ON FLASHING RED $A R R O W$. Average follow-up headway was 2.3 seconds for the flashing yellow and green ball permitted indications. The HCM default value of 2.1 seconds is consistent with the results (10). 
Table 5 Average Follow-Up Headway by Intersection

\begin{tabular}{c|ccccccc}
\hline City & ID & $\begin{array}{c}\text { PPLT } \\
\text { Display }^{b}\end{array}$ & PI $^{c}$ & $\begin{array}{c}\text { Left-Turn } \\
\text { Phasing }\end{array}$ & \multicolumn{2}{c}{ Follow-Up Hoadway (sec) } \\
\hline $\begin{array}{c}\text { Dallas } \\
\text { TX }\end{array}$ & 1 & 5-Vert. & GB & Lead & 100 & 2.3 & 0.7 \\
\hline $\begin{array}{c}\text { Dover } \\
\text { DE }\end{array}$ & 6 & 4-Cluster & FRA & Lead & 100 & 2.8 & 0.7 \\
\hline $\begin{array}{c}\text { Oakland } \\
\text { County } \\
\text { MI }\end{array}$ & 9 & 3-Vert. & FRB & Lag & 100 & 2.4 & 0.5 \\
\hline $\begin{array}{c}\text { College } \\
\text { Station } \\
\text { TX }\end{array}$ & 12 & 5-Horz. & GB & Lead & 100 & 2.3 & 0.6 \\
\hline $\begin{array}{c}\text { Seattle } \\
\text { WA }\end{array}$ & 15 & 4-Vert. & FYB & Lead & 100 & 2.3 & 0.5 \\
\hline $\begin{array}{c}\text { Portland } \\
\text { OR }\end{array}$ & 19 & 5-Cluster & GB & Lead & 100 & 2.2 & 0.4 \\
\hline $\begin{array}{c}\text { Cupertino } \\
\text { CA }\end{array}$ & 22 & 4-Vert. & FRA & Lead & 100 & 2.5 & 0.8 \\
\hline $\begin{array}{c}\text { Orlando } \\
\text { FL }\end{array}$ & 25 & 5-Cluster & GB & Lead & 100 & 2.3 & 0.5 \\
\hline
\end{tabular}

${ }^{a}$ Intersection Identification Number.

${ }^{b}$ Number of signal display sections $(3,4$, or 5$)$ - arrangement (Horizontal, Vertical, or Cluster).

${ }^{c}$ Permitted Indication $-\mathrm{G}=$ Green; $\mathrm{Y}=$ Yellow; $\mathrm{R}=$ Red; $\mathrm{B}=$ Ball; $\mathrm{A}=$ Arrow; $\mathrm{F}=$ Flashing.

${ }^{d}$ Number of Observations.

${ }^{e}$ Standard Deviation. 
Since follow-up headways occur only during the permitted phase of the signal cycle, the statistical analysis was focused completely on the variability in follow-up headway between types of PPLT signal displays and permitted indications. The analysis of the data indicated that the type of PPLT signal display and permitted indication did have a statistically significant effect.

Figure 7 presents the average follow-up headway for each PPLT signal display and indication combination along with the corresponding 95 percent CIs. Statistical evaluation of the differences found that the four-section cluster display with a flashing red arrow permitted indication had a significantly longer average follow-up headway time than all other PPLT signal display and permitted indication combinations. Further, the four-section vertical display with a flashing red arrow indication had a significantly longer average follow-up headway time than the five-section cluster display with a green ball permitted indication.

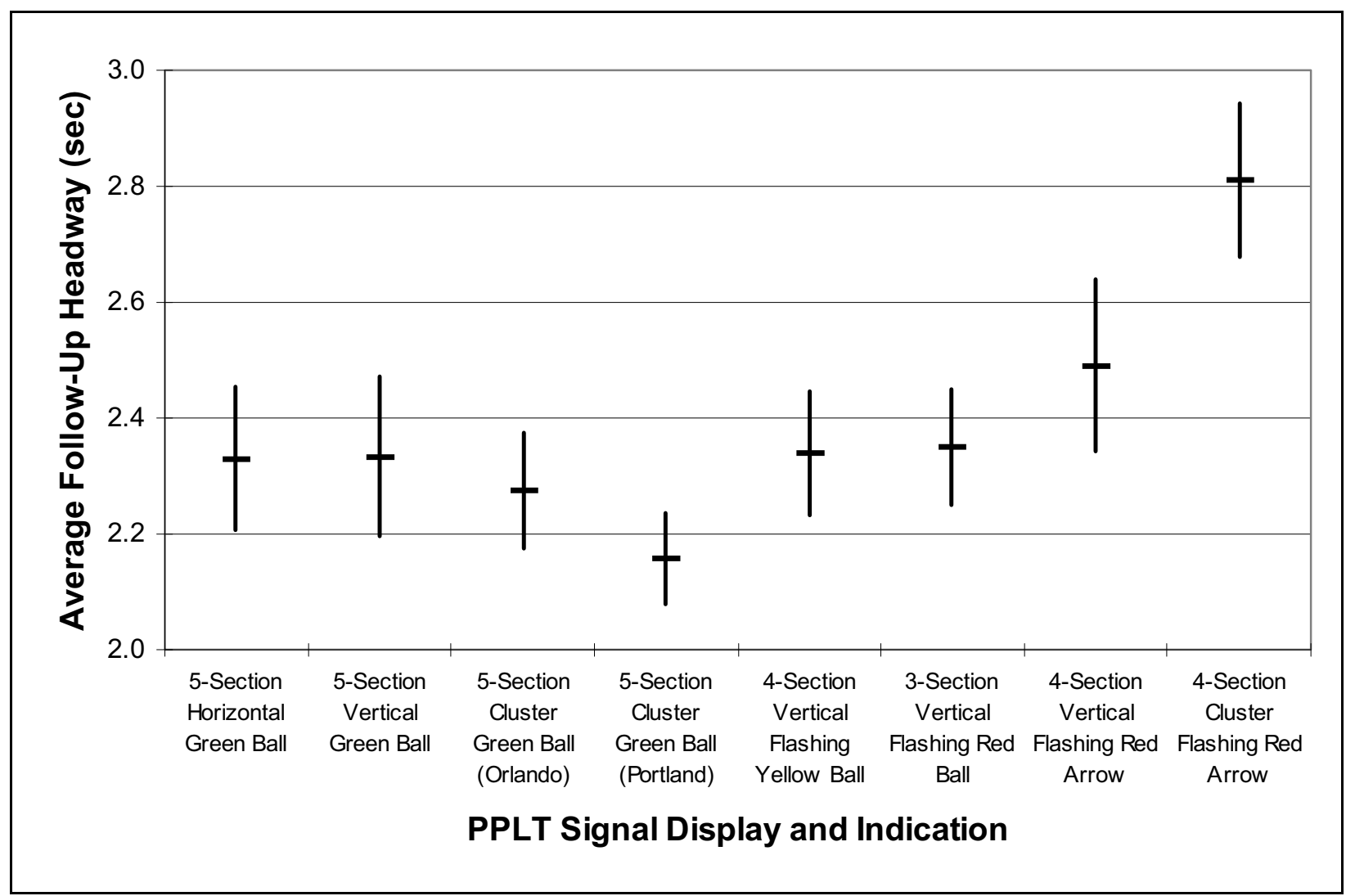

Figure 7 Average Follow-Up Headway and 95 Percent CIs by Display Type. 
The five-section cluster display with a green ball permitted indication was associated with the shortest average follow-up headway time. In contrast, the four-section cluster display with the flashing red arrow permitted indication had the longest average follow-up headway time. At least part of this difference can be explained by the different legal requirements (Uniform Vehicle Code) associated with the permitted indication. In other words, left-turn drivers are required to stop before making the permitted movement with a flashing red permitted indication while drivers facing a flashing yellow or green ball permitted indication are only required to yield. As expected, the four-section vertical display with a flashing red arrow permitted indication and the three-section vertical display with a flashing red ball permitted indication had the next highest average follow-up headway.

In general, there was no statistically significant difference between the five-section horizontal, five-section vertical, and five-section cluster displays using the green ball permitted indication. Similarly, there was no significant difference between the PPLT signal displays that used either a flashing yellow ball or steady green ball permitted indication. Therefore, the legal requirements associated with the permitted indication explain the differences in follow-up headway results. Follow-up headway is longer with the flashing red ball and red arrow permitted indications because drivers are required to stop before proceeding with the permitted left-turn. The exception to this finding was Oakland County. Although drivers are legally required to stop before making a permitted left-turn, Oakland County drivers seemed to interpret the meaning of the flashing red ball permitted indication the same as the yellow or green permitted indications. No supplemental sign describing the meaning of the flashing red ball indication is used in Oakland County.

\section{CONCLUSIONS}

The analysis showed that there was no difference in saturation flow rate and start-up lost time due to the type of PPLT signal display. Variation in saturation flow rate was caused by differences in operational characteristics and driver behavior between geographic locations. Higher saturation flow rates where found in locations where traffic pressure was perceivably greater, leading to more aggressive driving. Variations in start-up lost time were primarily related to differences in PPLT signal phasing. Lagging left-turn signal phasing was associated with lower start-up lost time values. The variation in response time between locations was related to differences in PPLT signal 
phasing although there was a correlated effect between the signal phasing, location, and the PPLT signal display used.

The follow-up headway study found the shortest headway associated with the five-section cluster display using a steady green ball permitted indication and the longest with the four-section cluster display using a flashing red arrow indication. The variation in follow-up headway was related to the legal requirements associated with the permitted indication. Drivers facing a flashing red display are required to stop before proceeding while drivers facing a steady green ball or flashing yellow indication are only required to yield.

\section{RECOMMENDATIONS}

The study results have led to several recommendations:

- The Highway Capacity and Quality of Service Committee should consider an ideal saturation flow rate default value of 2,000 vphgpl for PPLT. This default value would apply at locations with high traffic volumes, moderate to high demand flow rates, exclusive left-turn lanes, and good geometry. Although values greater that 2,000 vphgpl were found in this study, they appear to be site specific and may not applicable to all locations in the United States.

- Additional study is warranted to evaluate the differences in start-up and total lost time between leading and lagging left-turn phasing sequences. The results of this study found the average start-up lost time of the lagging left-turn sequence to be approximately 1.0 second less than the leading left-turn sequence. Additional data that support these findings may warrant separate lost time default values for leading and lagging left-turn phasing sequences, which can have a significant effect on capacity analysis. 


\section{ACKNOWLEDGMENTS}

Data described in this paper was obtained as part of the NCHRP 354(02) Project entitled An Evaluation of Traffic Signal Displays for the Protected/Permitted Left Turn Control. This project is being conducted by Kittelson \& Associates, Inc. in association with the Texas Transportation Institute. The NCHRP Contract Officer is Ray Derr.

\section{REFERENCES}

1. Fambro, D.B., G.D. Gaston, and C.M. Hoff. Comparison of Two Protected-Permitted Lead-Lag Left-Turn Phasing Arrangements. Report 989-1F. Texas Transportation Institute, Texas A\&M University System, College Station, TX, 1991.

2. Noyce, D.A. Development of a Uniform Traffic Control Device For Protected/Permited Left-Turn Control. Doctoral Dissertation, Texas A\&M University System, College Station, TX, 1999.

3. Fambro, D.B., C.J. Messer, and D.L. Woods. Guidelines for Signalized Left-Turn Treatments. Report FHWA-IP-81-4, FHWA. U.S. Department of Transportation, Washington, DC, 1981.

4. Manual on Uniform Traffic Control Devices. FHWA, U.S. Department of Transportation, Washington, DC, 1988.

5. Kittelson \& Associates, and the Texas Transportation Institute. Uniform Traffic Signal Displays for Exclusive/Permissive Left-Turn Control. NCHRP 3-54, Draft Final Report. FHWA, U.S. Department of Transportation, Washington, DC, 1996.

6. Bonneson, J.A., and P.T. McCoy. Evaluation of Protected/Permitted Left-Turn Traffic Signal Displays. Report TRP-02-27-92. Civil Engineering Department, University of Nebraska-Lincoln, Lincoln, NE, 1993.

7. Noyce, D.A., D.B. Fambro, and R.J. Koppa. Driver Understanding of Protected/ Permissive Left-Turn Signal Indications. In ITE 1996 Compendium of Technical Papers, Institute of Transportation Engineers, Washington, DC, 1996, pp. 233-237. 
8. Sobhi, N., D. Warren, H. Bissell, and S.C. Tignor. Signal Display for Left-Turn Control. FHWA, U.S. Department of Transportation, Washington, DC, August, 1991.

9. JHK \& Associates. Signal Displays for Left-Turn Control. Report DTFH61-85-C-00164. FHWA, U.S. Department of Transportation, Washington, DC, 1988.

10. Special Report 209: Highway Capacity Manual. Third Edition, TRB, National Research Council, Washington, DC, 1994.

11. Robertson, H.D., J.E. Hummer, and D.C. Nelson. Manual of Traffic Engineering Studies. ITE, Prentice Hall, Englewood Cliffs, NJ, 1994, pp. 69-87, 219-235.

12. Benioff, B., and T. Rorabaugh. A Study of Clearance Intervals, Flashing Operation, and Left-Turn Phasing at Traffic Signals. Report RD-78-46. Vol. 1, FHWA, U. S. Department of Transportation, Washington, DC, 1980.

13. Machemeh1, R.B., and A.M. Mechler. Comparative Analysis of Left-Turn Phase Sequencing. Report 258-2. Center for Transportation Research, University of Texas, Austin, TX, January, 1984.

14. Messer, C.J, and J.A. Bonneson. Capacity Analysis of Interchange Ramp Terminals. NCHRP 3-47, Final Report, FHWA, U.S. Department of Transportation, Washington, DC, 1997. 